\section{SAT0412 DOES THERAPEUTIC EDUCATION IMPROVE GOUT MANAGEMENT: THE EXPERIENCE OF LARIBOISIERE UNIVERSITY HOSPITAL PARIS-FRANCE}

Omar Al Tabaa ${ }^{1}$, Etienne Gaix-Fontaine ${ }^{1}$, Julia Herrou ${ }^{1}$, Frederic Lioté ${ }^{1,2}$, Thomas Bardin ${ }^{1,2}$, Pascal Richette ${ }^{1,2}$, Aline Frazier ${ }^{1}$, Hang Korng Ea ${ }^{1,2}$.

${ }^{1}$ Lariboisière Hospital, AP-HP, Rheumatology department, centre Viggo Petersen, Paris, France; ${ }^{2}$ University Paris Diderot, Paris, France

Background: Gout is a frequent and curable arthritis affecting $0.9 \%$ of adults in France. Its management remains suboptimal and less than one third of patients have efficient urate-lowering treatment (ULT). However, when individualized information were given and patients engaged in their care a treat-to-target strategy permits to achieve serum urate level (SU) at target (SU $<360 \mu \mathrm{mol} / \mathrm{L})$ in more than $95 \%$ of patients.

Therapeutic education sessions (TES) may improve patient knowledges, gout flare and ULT management.

Objectives: To assess the percentage of patients achieving SU target at 1 year after a TES

Methods: TES was set up in the department since January 2014. Patients willing to participate to TES responded to a questionnaire and were interviewed with a nurse assessing their knowledges, believes and gout representations. Each TES included 5 to 8 patients and was conducted according to participants' needs. We retrospectively included all

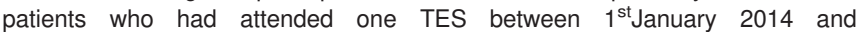
$31^{\text {th }}$ December 2017 and who had at least one visit between 9 and 15 months later.

TES patients were matched in 1:1 with no-TES patients regarding age, sex and referent practitioner.

For all patients were collected: demographics, disease duration, SU, treatments and comorbidities (type 2 diabetes, chronic kidney disease, hypertension, and cardiovascular diseases).

Results: Overall, 54 TES patients were included and matched with 54 non-TES patients. Patients' characteristics (demographics, disease duration, SU, treatments and comorbidities) were similar at baseline except for the body mass index (BMI) and the follow-up. BMI was higher (31.0 \pm 5.7 vs $\left.28.4 \pm 5.0 \mathrm{~kg} / \mathrm{m}^{2}, \mathrm{p}=0.03\right)$ and the final visit shorter $(11 \pm 3.6$ vs $14.4 \pm 4.8$ months, $p=0,001)$ in no-TES patients than in TES patients, respectively.

At final visit, 36 TES patients (67\%) and 34 no-TES patients $(63 \%)$ reached the SU target $(<360 \mu \mathrm{mol} / \mathrm{L}) \quad(\mathrm{p}=0.84)$ (Table 1$)$. Moreover, 22 $(41 \%)$ TES patients and 18 (33\%) no-TES patients had a final SU < $300 \mu \mathrm{mol} / \mathrm{L}(\mathrm{p}=0.43)$. There were no differences between groups (TES vs no-TES patients respectively) for: final SU (342 $\mu \mathrm{mol} / \mathrm{l} \pm 94$ vs $338 \pm$

Table 1. Patient's characteristics for gout at the end of the follow-up

\begin{tabular}{|c|c|c|c|c|c|}
\hline & \multicolumn{2}{|c|}{ Baseline } & \multicolumn{2}{|c|}{$\begin{array}{l}\text { End of follow- } \\
\text { up }\end{array}$} & \multirow[t]{2}{*}{$\begin{array}{c}p \\
\text { value }\end{array}$} \\
\hline & TES & $\begin{array}{l}\text { No- } \\
\text { TES }\end{array}$ & TES & $\begin{array}{l}\text { No- } \\
\text { TES }\end{array}$ & \\
\hline $\begin{array}{l}\text { Patient with serum urate }<360 \\
\mu \mathrm{mol} / \mathrm{L}, \mathrm{n}(\%)\end{array}$ & $0(0 \%)$ & $0(0 \%)$ & $\begin{array}{c}36 \\
(67 \%)\end{array}$ & $\begin{array}{c}34 \\
(63 \%)\end{array}$ & 0,84 \\
\hline $\begin{array}{l}\text { Patient with serum urate }<300 \\
\mu \mathrm{mol} / \mathrm{L}, \mathrm{n}(\%)\end{array}$ & $0(0 \%)$ & $0(0 \%)$ & $\begin{array}{c}22 \\
(41 \%)\end{array}$ & $\begin{array}{c}18 \\
(33 \%)\end{array}$ & 0,43 \\
\hline $\begin{array}{l}\text { Serum urate concentration ( } \mu \mathrm{mol} / \\
\mathrm{L}) \text {, mean }(\mathrm{SD})\end{array}$ & $\begin{array}{r}533 \\
(105)\end{array}$ & $\begin{array}{l}528 \\
(97)\end{array}$ & $\begin{array}{r}342 \\
(94)\end{array}$ & $\begin{array}{l}338 \\
(71)\end{array}$ & 0,84 \\
\hline Taking ULT & $\begin{array}{c}21 \\
(39 \%)\end{array}$ & $\begin{array}{c}19 \\
(35 \%)\end{array}$ & $\begin{array}{c}48 \\
(89 \%)\end{array}$ & $\begin{array}{c}48 \\
(96 \%)\end{array}$ & 0,16 \\
\hline Allopurinol, n (\%) & $\begin{array}{c}16 \\
(30 \% 5)\end{array}$ & $\begin{array}{c}12 \\
(22 \%)\end{array}$ & $\begin{array}{c}22 \\
(41 \%)\end{array}$ & $\begin{array}{c}22 \\
(44 \%)\end{array}$ & 0,89 \\
\hline Febuxostat, n (\%) & $5(9 \%)$ & $\begin{array}{c}7 \\
(13 \%)\end{array}$ & $\begin{array}{c}26 \\
(48 \%)\end{array}$ & $\begin{array}{c}26 \\
(52 \%)\end{array}$ & 0,84 \\
\hline \multicolumn{6}{|l|}{ ULT dose } \\
\hline Allopurinol (mg/day), mean (SD) & $\begin{array}{c}196 \\
(169)\end{array}$ & $\begin{array}{l}183 \\
(41)\end{array}$ & $\begin{array}{c}284 \\
(102)\end{array}$ & $\begin{array}{l}241 \\
(76)\end{array}$ & 0,22 \\
\hline Febuxostat (mg/day), mean (SD) & $\begin{array}{l}100 \\
(30)\end{array}$ & $86(10)$ & $92(26)$ & $83(13)$ & 0,32 \\
\hline $\begin{array}{l}\text { Taking hyperuricemia therapy, } \mathrm{n} \\
\text { (\%) }\end{array}$ & $\begin{array}{c}13 \\
(24 \%)\end{array}$ & $\begin{array}{c}16 \\
(30 \%)\end{array}$ & $\begin{array}{c}8 \\
(15 \%)\end{array}$ & $\begin{array}{c}6 \\
(11 \%)\end{array}$ & 0,77 \\
\hline Aspirine, $\mathrm{n}(\%)$ & $6(11 \%)$ & $\begin{array}{c}8 \\
(15 \%)\end{array}$ & $2(4 \%)$ & $2(4 \%)$ & 1 \\
\hline Thiazide diuretics, n (\%) & $5(9 \%)$ & $\begin{array}{c}7 \\
(13 \%)\end{array}$ & $\begin{array}{c}6 \\
(11 \%)\end{array}$ & $3(6 \%)$ & 0,49 \\
\hline Furosemide, n (\%) & $\begin{array}{c}6 \\
(11 \%)\end{array}$ & $\begin{array}{c}7 \\
(13 \%)\end{array}$ & $2(4 \%)$ & $2(4 \%)$ & 1 \\
\hline
\end{tabular}

$\mathrm{ULT}=$ urate-lowering therapy
71, $\mathrm{p}=0.84)$, ULT (89\% vs 96\%, $\mathrm{p}=0.16)$, ULT dosage and hyperuricemic therapy $(15 \%$ vs $11 \%, p=0.77)$

Conclusion: The percentage of patients achieving SU target after one single TES was high compare to literature data. However, it was not different from usual care achieved in our department, a tertiary care center expert in gout management. The diffusion of our savoir-faire and the TES will improve gout management.

\section{REFERENCE}

[1] Doherty M, Jenkins W, Richardson H, Sarmanova A, Abhishek A, Ashton $D$, et al. Efficacy and cost-effectiveness of nurse-led care involving education and engagement of patients and a treat-to-target urate-lowering strategy versus usual care for gout: a randomised controlled trial. The Lancet. 2018;392(10156):1403-1412

Disclosure of Interests: Omar Al Tabaa: None declared, Etienne GaixFontaine: None declared, Julia Herrou: None declared, Frederic Lioté Grant/research support from: institutional grants from Grunenthal, Ipsen Pharma/Menarini, Novartis, SOBI for the European Crystal Network Workshops, Consultant for: Grunenthal, Novartis, Thomas Bardin Consultant for: Astrazeneca, Grunenthal, Horizon, Novartis, Speakers bureau: Astella AstraZeneca, Grunenthal., Pascal Richette Consultant for: Grunenthal, Horizon, Speakers bureau: AstraZeneca, Grunenthal, Aline Frazier: None declared, Hang Korng Ea: None declared

DOI: 10.1136/annrheumdis-2019-eular.4032

\section{SAT0413 SIZE MATTERS - EXTENT OF MONOSODIUM URATE DEPOSITS BUT NOT SERUM URATE LEVEL PREDICTS COMPLETE RESOLUTION OF MONOSODIUM URATE CRYSTAL DEPOSITS IN PATIENTS WITH GOUT}

Sara Bayat $^{1}$, Hanna Ellmann ${ }^{2}$, Elizabeth Araujo ${ }^{3}$, Bernhard Manger $^{3}$,

Melanie Hagen ${ }^{3}$, Arnd Kleyer ${ }^{3}$, Alexandeer Cavallaro ${ }^{4}$, Michael Lell ${ }^{5}$ Hannah Schenker ${ }^{2}$, David Simon ${ }^{2}$, Koray Tascilar $^{2}$, Herbert S.B. Baraf ${ }^{6}$, Georg Schett ${ }^{2}$, Jürgen Rech ${ }^{3}$. ${ }^{1}$ Friedrich-Alexander-University Erlangen-Nürnberg (FAU), Universitätsklinikum Erlangen, Department of Internal Medicine 3 Rheumatology and Immunology, Erlangen, Germany., Erlangen, Germany ${ }^{2}$ Friedrich-Alexander-University Erlangen-Nürnberg (FAU), Universitätsklinikum Erlangen, Department of Internal Medicine 3 - Rheumatology and Immunology Erlangen, Germany., Erlangen, Germany; ${ }^{3}$ Friedrich-Alexander-University Erlangen-Nürnberg (FAU), Universitätsklinikum Erlangen, Department of Internal Medicine 3-Rheumatology and Immunology, Erlangen, Germany., Erlangen, Germany, ${ }^{4}$ Friedrich-Alexander-University Erlangen-Nürnberg (FAU), Universitätsklinikum Erlangen, Department of Radiology, Erlangen, Germany; ${ }^{5}$ Klinikum Nuernberg, Paracelsus Medical University Nuernberg, Department of Radiology and Nuclear Medicine, Nuernberg, Germany; ${ }^{6}$ Center for Rheumatology and Bone Research, Wheaton, Division of Rheumatology, The George Washington University, Washington, United States of America

Background: Gout is based on the deposition of monosodium urate (MSU) crystals. While it is well established that life-style intervention and/ or conventional urate lowering therapy can lead to a decrease in serum urate levels, the impact of such interventions to resolve already existing MSU deposits is very limited.

Objectives: In this study we wanted to determine if and to what extent MSU deposits resolve if patients follow structured life-style intervention or continuously conventional urate lowering therapy.

Methods: Subjects with diagnosis of gout and the presence of MSU deposits in the feet in baseline dual energy CT (DECT) scan, received either life-style intervention only $(\mathrm{N}=24)$ or additional conventional urate lowering therapy (allopurinol: $\mathrm{N}=29$, febuxostat: $\mathrm{N}=22$, benzbromarone $\mathrm{N}=2$ ) for a mean period of 18 months before receiving a follow-up DECT examination. MSU deposits were quantified by volumetric measurement and semi quantitative scoring at baseline and follow up.

Results: Serum uric acid (SUA) level decreased from $7.2 \pm 1.7$ to 6.7 $\pm 1.7 \mathrm{mg} / \mathrm{dl}$ with life-style intervention; from $7.0 \pm 1.5$ to $5.5 \pm 1.8 \mathrm{mg} / \mathrm{dl}$ with allopurinol and from $7.8 \pm 3.0$ to $5.1 \pm 2.5 \mathrm{mg} / \mathrm{dl}$ with febuxostat. MSU volume significantly decreased in patients undergoing life-style intervention (baseline: $0,07 \mathrm{~cm} 3 \pm 0,09$; follow up: $0,05 \pm 0,15 \mathrm{~cm} 3 ; \mathrm{p}=0.007$ ), treatment with allopurinol $(0,11 \pm 0.15 \mathrm{~cm} 3$ to follow up: $0.02 \pm 0,04 \mathrm{~cm} 3$, $\mathrm{p}<0.001$ ) or febuxostat (MSU volume baseline: $0.99 \pm 2.8$ to follow up: $0.64 \pm 2.09 ; \mathrm{p}=0.001)$. With respect to conversion from a $\mathrm{DECT}+$ into a DECT- state, baseline MSU deposit burden, but not baseline SUA level or decrease in SUA level, was associated with reaching a DECT- state. 
Thus patients with smaller deposits were more likely to completely resolve the deposits.

Conclusion: We show that both life-style intervention and conventional urate lowering drug therapy reduce the volume of monosodium urate deposits. The size of MSU deposits, but not serum urate level, was the main factor that influenced complete resolution of deposits. This finding reemphasizes that the burden of deposits essentially defines the likelihood and time for complete resolution of gout.

\section{REFERENCES}

[1] Manger B, Lell M, Wacker J, Schett G, Rech J. Detection of periarticular urate deposits with dual energy CT in patients with acute gouty arthritis. Ann Rheum Dis. 2012;71(3):470-2.

[2] Bongartz T, Glazebrook KN, Kavros SJ, Murthy NS, Merry SP, Franz WB, 3rd, et al. Dual-energy CT for the diagnosis of gout: an accuracy and diagnostic yield study. Ann Rheum Dis. 2015;74(6):1072-7.

[3] Bayat S, Aati O, Rech J, Sapsford M, Cavallaro A, Lell M, et al. Development of a Dual-Energy Computed Tomography Scoring System for Measurement of Urate Deposition in Gout. Arthritis Care Res (Hoboken). 2016;68(6):769-75.

Disclosure of Interests: Sara Bayat: None declared, Hanna Ellmann: None declared, Elizabeth Araujo: None declared, Bernhard Manger: None declared, Melanie Hagen: None declared, Arnd Kleyer Grant/research support from: Lilly, Consultant for: Lilly, Speakers bureau: Abbvie, Alexandeer Cavallaro: None declared, Michael Lell: None declared, Hannah Schenker None declared, David Simon Grant/research support from: Novartis, Consultant for: Lilly, Speakers bureau: Janssen, Koray Tascilar: None declared, Herbert S.B. Baraf: None declared, Georg Schett: None declared, Jürgen Rech Grant/research support from: Bristol-Myers Squibb and Celgene (greater than $\$ 10,000$ ), Consultant for: Bristol-Myers Squibb, Celgene, Chugai, GlaxoSmithKline, Janssen, Eli Lilly, Novartis, Roche, Sanofi Aventis, and UCB (in total more than $\$ 10,000$ ), Speakers bureau: Bristol-Myers Squibb, Celgene, Chugai, GlaxoSmithKline, Janssen, Eli Lilly, Novartis, Roche, Sanofi Aventis, and UCB (in total more than $\$ 10,000$ ) DOI: 10.1136/annrheumdis-2019-eular.3989

\section{SAT0414 CLINICAL PRESENTATION OF PAGET DISEASE OF BONE: IS IT CHANGING? A RETROSPECTIVE ANALYSIS ON 368 PATIENTS}

Chiara Crotti, Francesca Zucchi, Andrea Becciolini, Luigi Sinigaglia, Massimo Varenna. ASST-Gaetano Pini-CTO, Division of Rheumatology, Milan, Italy

Background: In the last few years, it has been reported a secular change of Paget disease of bone (PDB), expressed as a reduction of prevalence $^{1}$ and severity, assessed by disease extent ${ }^{2}$.

Objectives: To retrospectively evaluate the baseline clinical and demographic characteristics of a contemporary cohort of patients affected by PDB, compared with a cohort of a previous decade ${ }^{3}$.

Methods: Data were retrospectively extracted from a monocentric registry, which included PDB patients at their first evaluation in a tertiary rheumatology Center between January 2000 and September 2018. Descriptive data of baseline characteristics included demographics, presenting manifestation and diagnostic procedures (diagnosed by chance or by investigations requested for specific clinical manifestations), extent of PDB, and biochemical data. Patients were divided into two groups according to the year of first evaluation: group 1 before July 2007, group 2 after July 2007. Comparisons between the two groups were performed by $T$ test and chi-square test; logistic regression was used to analyze the association between disease extent and other collected variables.

Results: The overall population included 368 patients (males (M) 57.6\%, mean age at diagnosis [ \pm standard deviation, SD] $62.0 \pm 12.4 \mathrm{yrs}$ ). Diagnosis was made by chance in $43.8 \%$ cases, $54.3 \%$ patients had symptoms at disease onset; $49.5 \%$ was monostotic, mean serum alkaline phosphatase at presentation (sALP) was $198.5 \pm 167.5 \mathrm{UI} / \mathrm{L}$.
Group 1 included 217 patients (M 56.2\%, mean age at diagnosis 61.0 $\pm 11.6 \mathrm{yrs}, 6.5 \%$ family history of PDB; $45.6 \%$ diagnosed by chance, $51.2 \%$ had symptoms at disease onset, mean sALP $218.9 \pm 11,7,43.3 \%$ monostotic). Group 2 included 151 subjects (M 59.6\%, mean age at diagnosis $64.3 \pm 11.1 \mathrm{yrs}, 7.3 \%$ family history of PDB; $41.1 \%$ diagnosed by chance, $62.9 \%$ had symptoms at disease onset, mean sALP 162.7 $\pm 14,2,58.3 \%$ monostotic).

Poliostotic disease was significantly higher in Group 1 vs Group 2 $(p=0.007)$, and the odd to have a poliostotic disease was higher in Group 1 [OR 1.82 (IC 1.2-2.8), $\mathrm{p}<0,005$ ]. sALP was significantly higher in Group 1 vs Group $2(218,9 \pm 11,7$ vs $162,7 \pm 14,2 ; p=0,003)$. No differences were found in sex, age at diagnosis, presence of family history of PDB between patients diagnosed incidentally or by symptoms.

Conclusion: Our data confirm the reduction of clinical severity, assessed by the proportion of skeleton involved, and the decrease of biochemical markers over time. The reduction of the disease extent is consistent with a serological biomarker of the disease, such as mean SALP levels.

\section{REFERENCES}

[1] Michou L, et al. JBS 2016;83: 650-655.

[2] Tan A, Ralston SH. Calcif Tissue Int 2014;95:385-392.

[3] Varenna M, et al. J Rheum 2010;37:155-160.

Disclosure of Interests: Chiara Crotti: None declared, Francesca Zucchi: None declared, Andrea Becciolini: None declared, Luigi Sinigaglia Speakers bureau: Yes, I,ve been invited speaker by Amgen, Ely Lilly, UCB, Abbvie, Roche and BMS., Massimo Varenna: None declared DOI: 10.1136/annrheumdis-2019-eular.4832

\section{SAT0415 HIGH BODY FAT OF TRUNK IS POSITIVELY CORRELATED WITH SERUM URIC ACID IN MALE GOUT PATIENTS}

LI Qianhua, Lijuan Yang, Yan-Hui Xu, Chao Deng, Hui-Wen Lu, Xin-Yun Du, Jinjian Liang, Jianzi Lin, Yingqian Mo, Lie Dai. Sun Yat-sen Memorial Hospital, Sun Yat-sen University, Department of Rheumatology, Guangzhou, China

Background: Obesity is an important risk factor of gout which is defined by body mass index (BMI). However, BMI has been challenged for the limitation of failure to differentiate comprising tissues of the body. More accurate body composition (BC) has been frequently recommended to assess metabolic status.

Objectives: To investigate the characteristics of $\mathrm{BC}$ in gout patients and its clinical significance.

Methods: Consecutive gout patients who fulfilled the 2016 ACR/EULAR classification criteria were recruited between June 2017 and December 2018. BC was assessed by bioelectric impedance analysis including body fat percentage $(\mathrm{BF} \%)$, the mass and distribution of muscle and fat in trunk and appendicular extremities. Demographic information, clinical characteristics and comorbidities were collected. Overfat was defined by BF\% $\geq 25 \%$ for male and $>35 \%$ for female.

Results: Among 362 recruited gout patients, $96.1 \%$ were male and the median age was $38(30,50)$ years, mean serum uric acid (sUA) was $9.2 \pm 2.2 \mathrm{mg} / \mathrm{dl}$, $18.0 \%$ presented tophi. The mean BF\% was $25.8 \pm 6.4 \%$ with $53.6 \%$ overfat. Male gout patients with overfat $(53.7 \%$ ) showed more affecting joints, higher sUA and higher prevalence of comorbidities than those without overfat $(P<0.05$, Figure 1). Their BF\%, trunk BF\% and limb $\mathrm{BF} \%$ were positively correlated with count of affecting joints, sUA, hypertension, metabolic syndrome and fatty liver in Spearman correlation analy sis, respectively $(r=0.133 \sim 0.424$, all $P<0.05)$. The male patients with overfat also presented higher BMI and waist circumstance (WC), higher trunk/limb $\mathrm{BF} \%$ ratio $(P<0.05$, Figure 1$)$. Their $\mathrm{BF} \%$, trunk $\mathrm{BF} \%$ and limb $\mathrm{BF} \%$ were also positively correlated with $\mathrm{BMI}$ and WC, respectively $(r=0.604 \sim 0.755$, all $P<0.05)$. After adjustment for age, duration, family his tory, eGFR, hypertension, diabetes mellitus, dyslipidemia, metabolic syndrome, fatty liver, coronary heart diseases, urolithiasis, BMI and WC multivariable linear regression showed that $\mathrm{BF} \% \quad(\beta=0.072,95 \% \mathrm{Cl}$ 